\section{Independent panel will oversee US research on Gulf War illnesses}

[WASHINGTON] President Bill Clinton is appointing an independent, nongovernment panel to oversee research by the US Department of Defense (DOD) into the relationship between possible chemical and biological exposures and the ill-defined collection of maladies known as Gulf War illnesses. Clinton said in a statement that retired senator Warren Rudman would head the panel. Its other four or so members have yet to be named and its mandate will last at least a year.

The move is a response to a final report Clinton received on 31 October from his Presidential Advisory Committee on Gulf War Veterans' Illnesses (PACGWI), which calls for the DOD to be stripped of authority for overseeing research on chemical and biological exposures and their relationship to Gulf War illnesses (see Nature 390, 4; 1997).

The PACGWI report said that the Pentagon's investigation had been hampered by "an institutional culture and pervasive inclination" to dismiss evidence of possible chemical exposure of US troops. It also sharply criticized the Pentagon for funding studies that had not been competitively reviewed, and urged that it immediately stop.

Clinton will also ask the National Academy of Sciences to monitor continuing research on associations between Gulf War service and current illnesses for the purposes of future research and disability compensation.

\section{First UN text on science and human rights}

[PARIS] Almost 50 years after the adoption of the 1948 United Nations Universal Declaration of Human Rights, the 186 member states of Unesco were this week scheduled to adopt the first UN text governing science and human rights, the "universal declaration on the human genome and human rights".

The text consists of a set of broad principles affirming the rights and liberties of individuals against genetic discrimination, while upholding the principle of scientific liberty.

As Nature went to press, it appeared that the only prominent absences from the signatories would be Canada, which feels the text should include more specific references to the rights of the handicapped, ethnic minorities and women, and Israel, which opposes an article banning human cloning, arguing that it is inappropriate to include detailed provisions governing medical and research practices.

As a declaration, the text is not legally binding on signatories. But the possibility that it may be developed into a treaty cannot be discounted, says Nöelle Lenoir, who chairs Unesco's International Bioethics Committee (IBC). The declaration confers on the IBC the role of overseeing the implementation of the text's provisions, and the IBC hopes to advise countries on setting up ethics committees.

\section{Brain science centre opens in Japan}

[TOKYO] Japan's Institute of Physical and Chemical Research (RIKEN) has opened a Brain Science Institute that will play a central role in an important Japanese initiative to develop research on the brain. The institute, headed by Masao Ito, one of Japan's leading neuroscientists, is part of a plan by the government to spend $¥ 2,000$ billion (US $\$ 16$ billion) on a wide range of neuroscience over the next 20 years (see Nature 382, 105; 1996).

At the opening ceremony on 10 November, Akito Arima, president of RIKEN, expressed delight at the speed with which the new institute had been established, and said that this had been due to a successful combination of a "bottom-up approach" by scientists and a "top-down" approach by government and politicians who have recently become strong supporters of science.

\section{BSE report sees progress on EU science advice}

[PARIS] The European Parliament last week wrapped up its investigation of the bovine spongiform encephalopathy (BSE) crisis. The conclusion of the final report by the temporary committee on BSE is that the European Commission (EC) has made substantial progress in reforming its system of providing scientific advice. But the report "deplores" that although most of the EC officials responsible for handling BSE have been assigned to other duties, none has been otherwise disciplined.

The conclusion lifts the parliament's earlier threat to sack the EC's commissioners if its demands were not met. Some observers argue that the parliament has been highly successful in using the threat to obtain changes in the way the EC operates, in particular a radical reform of its scientific committees to distance them from economic interests and make their deliberations more open (see Nature 385, 664; 1997). Details of the committees and their proceedings are on http://europa.eu.int/en/comm/spc/spc.html

\section{CERN continues search for director-general}

[GENEVA] The committee of council of CERN, the European Laboratory for Particle Physics, has once again failed to select a new director-general to succeed Christopher Llewellyn Smith, whose term of office expires at the end of next year. At a special meeting last week, the committee managed to reduce the three-man shortlist to a single candidate, Albrecht Wagner, directorgeneral of research at DESY, Germany's national research centre for particle physics.

But it also added a last-minute candidate, Luciano Maiani, head of INFN, Italy's National Institute for Nuclear Physics, who is currently also president of CERN council. A final decision must be made by CERN council at the end of December. Should Maiani be selected, the same meeting would have to select a new president of council.

\section{Brookhaven reactor faces further delay}

[WASHINGTON] The US Department of Energy says it will not be able to name a new contractor for the Brookhaven National Laboratory this month, as promised, because of a new law requiring it to give the Congress 60 days' notice before awarding such a contract. Officials say the delay will, in turn, push back by at least two months any decision to reopen the High Flux Beam Reactor.

A tritium leak from a storage tank at the reactor led the department to fire the existing contractor, Associated Universities Inc. (AUI), in May (see Nature 387, 114; 1997). The latest delay leaves the troubled laboratory in limbo with an acting director and AUI still in charge. The energy department has received two bids to run the laboratory, one from the State University of New York at Stony Brook in partnership with Battelle, and another from the Illinois Institute of Technology and Westinghouse.

\section{Global change expert nominated for Scripps}

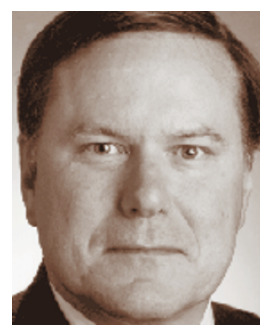

[SAN FRANCISCO] Charles F. Kennel (left), an expert in global change and global observation systems, has been nominated to be director of the Scripps Institution of Oceanography in La Jolla, California. It is part of the University of California, San Diego, and has a \$103million budget, 300 research programmes and a four-ship research fleet.

Kennel has been executive vice chancellor since 1996 at the University of California, Los Angeles, where he has worked for 30 years. He served as associate administrator for the National Aeronautics and Space Administration's Mission to Planet Earth Program from 1994 to 1996, and won the 1997 James Clerk Maxwell Prize for contributions to basic plasma physics and plasma astrophysics. The UC regents are expected to consider Kennel's nomination at their January meeting. 